\title{
PENERAPAN MODEL BLENDED POE2WE BERBASIS GOOGLE CLASSROOM SEBAGAI INOVASI PEMBELAJARAN DI SEKOLAH MENENGAH ATAS DI ERA REVOLUSI INDUSTRI 4.0
}

\author{
Afiif Curnitasari ${ }^{1}$, Nana ${ }^{2}$ \\ ${ }^{1}$ Mahasiswa Program Studi Pendidikan Fisika,Universitas Siliwangi \\ ${ }^{2}$ Dosen Program Studi Pendidikan Fisika, Universitas Siliwangi \\ Email: afiifcurnitasari05@gmail.com
}

\begin{abstract}
Abstrak:The purpose of this paper is o describe the use of digital in learning in the era of the industrial revolution 4.0. This writing is realized by the lack of digital utilization in terms of education in Indonesia. For this reason the need for the application of blended POE2WE as a learning innovation in high school Developing digital learning innovation with the Blended POE2WE model aims (1) to access knowledge without time and space limitation, (2) to establish internet-based communication, (3) to make learning easier and more enjoyable, and (4) to create more interactive and innovative learning process (Nana,2019: 2548-8325). The method was literacy (library study).In Learning Students are expected to be more active and creative to utilize digital in the industrial Revolution 4.0 era.
\end{abstract}

Keywords: Blended POE2WE Model, Industrial Revolution 4.0

\begin{abstract}
ABSTRAK: Tujuan penulisan ini untuk mendeskripsikan pemanfaatan digital dalam pembelajaran di era revolusi industry 4.0. Penulisan ini disadari oleh masih kurangnya pemanfaatan digital dalam hal Pendidikan di Indonesia. Untuk itu perlunya penerapan blended POE2WE sebagai inovasi pembelajaran di sekolah menengah atas.Pengembangan inovasi pembelajaran digital dengan model Blended POE2WE bertujuan untuk (1) mengakses pengetahuan setiap saat tak terbatas waktu dan tempat (2) menjalin komunikasi berbasis internet (3) menciptakan pembelajaran lebih mudah dan menyenangkan. (4) menciptakan proses pembelajaran lebih interaktif dan inovati (Nana,2019: 2548-8325). Metode penelitian yang digunakan adalah literasi (studi pustaka). Dalam Pembelajaran Peserta didik di harapkan menjadi lebih aktif dan kreatif untuk memanfaatkan digital di era Revolusi Industri 4.0.
\end{abstract}

Kata kunci: Model Blended POE2WE, Revolusi Industri 4.0

\section{PENDAHULUAN}

Undang-undang Republik Indonesia mengenai sistem pendidikan nasional pada Bab 1 Pasal 1 menyatakan bahwa Pendidikan merupakan usaha secara sadar dan terencana untuk mewujudkan suasana belajar dan proses pembelajarannya agar peserta didik aktif dalam mengembangkan potensi yang terdapat dalam dirinya untuk memiliki kekuatan spiritual keagamaan,pengendakian diri, kepribadian, kecerdasan, ahlak yang mulia dan keterampilan yang diperlukan oleh dirinya sendiri, bangsa dan negara serta masyarakat (UUD RI,2003). Dan Berdasarkan Permendikbud RI Nomor 65 Tahun 2013 tentang standar proses, pemerintah 
telah menetapkan kebijakan penggunaan Teknologi Informasi dan Komunikasi (TIK) dalam pembelajaran pada Kurikulum 2013 sesuai dengan pendidikan SD, SMP, SMA dan sederajat, disebutkan pada butir ke 13 prinsip pembelajaran yang digunakan yaitu pemanfaatan teknologi informasi dan komunikasi untuk meningkatkan efisiensi dan efektivitas pembelajaran

Pendidikan yang bersifat konvensional yang hanya dibatasi pada pertemuan di sekolah juga tidak dapat mengembangkan kemampuan dan pengetahuan yang dimiliki oleh peserta didik. Waktu yang tersedia bagi pendidik dan peserta didik untuk bertatap muka secara langsung di ruang kelas sangat terbatas. Selain itu proses penyampaian bahan ajar hampir sepenuhnya dilakukan dalam ruang kelas yang menyebabkan penyampaikan bahan ajar bisa saja terlambat atau bahkan tidak tersampaikan jika pertemuan terdapat kendala. Permasalahan tersebut dapat menyebabkan perkembangan peserta didik menjadi terhambat. Hasil belajar yang rendah dapat diakibatkan karena siswa kurang aktif dalam proses belajar mengajar. Faktor kecil yang dapat mempengaruhi rendahnya hasil belajar siswa adalah karena pembelajaran yang disajikan masih dalam bentuk yang kurang menarik, sehingga terkesan sulit dipahami sehingga siswa tidak terlalu menguasai konsep dasar yang terkandung dalam materi pelajaran fisika. Hal tersebut dapat menghambat kreativitas siswa dalam menjawab soal, yang akhirnya hasil belajar siswa menjadi rendah (Gumay, O. P. U., \& Framanta, A, 2019).

Pada era digital atau era informasi sekarang ini ilmu pengetahuan dan teknologi berkembang dengan pesat. Perkembangan ini memiliki dampak semakin terbuka dan tersebarnya informasi dan pengetahuan dari dan ke seluruh dunia menembus batas jarak, tempat, ruang dan waktu (Nana \& Surahman. 2019: 82-83). Jalan keluar untuk mengatasi permasalahan tersebut maka di buatlah E-Learning (Sukamto, 2012). E-Learning ini dapat bermanfaat untuk menambah pertemuan walaupun secara tidak langsung dalam proses pembelajaran agar dapat meningkatkan kemampuan dan pengetahuan peserta didik.

E-Learning merupakan suatu istilah yang dapat kita temukan dalam dunia komputer atau internet. Kata e-learnig terdiri atas 2 (dua) bagian yaitu "e" yang berarti "elektronik" dan "learning" yang berarti "pembelajaran". Jadi kata e-learning dapat diartikan sebagai suatu sistem pembelajaran yang menggunakan perangkat elektronik sebagai media pembelajarannya. (Rahmasari \& Rismiati, 2013:27). Selanjutnya dikatakan bahwa sistem $e$ learning diharapkan bukan sekedar menggantikan metode dan materi pengajaran 
konvensional tetapi dapat juga menambahkan metode maupun strategi baru dalam proses pembelajaran.

Dengan penerapan e-learning dapat memberikan manfaat pada peserta didik, yaitu:

a. Adanya peningkatan interaksi peserta didik dengan sesamanya dan dengan pengajar,

b. Tersedianya sumber-sumber pembelajaran yang tidak terbatas,

c. E-learning yang dikembangkan secara benar akan efektif dalam meningkatkan kualitas lulusan dan kualitas institusi pendidikan,

d. Terbentuknya komunitas pembelajar yang saling berinteraksi, saling memberi dan menerima serta tidak terbatas dalam satu lokasi,

e. Meningkatkan kualitas pengajar karena dimungkinkan menggali informasi secara lebih luas dan bahkan tidak terbatas.,

f. Media online; yaitu media belajar mandiri yang di-deliver dan dapat diakses secara online via podcast/vodcast, media streaming (video streaming, audio streaming), halaman web,dolumen yang dapat didwonload (slideshare,dll), ruang chatting,pesan instan (instant messaging),email,forum,twitter,blog, wiki, dan lain-lain. (Nana \& Surahman. 2019: 83)

\section{METODE PENELITIAN}

Metode yang digunakan dalam penulisan ini berupa studi kepustakan. Data dikumpulkan untuk dianalisis kemudia disajikan dalam hasil dan pembahasan agar dapat di buat kesimpulan.

\section{HASIL DAN PEMBAHASAN}

\subsection{Blended POE2WE}

Kerangka teori POE2WE ini dibangun berdasarkan pandangan dari beberapa teori yang mengkerangkai model pembelajaran POE2WE. Dalam POE2WE dipadukan tiga jenis interaksi yang meliputi interaksi sosial, inetraksi muatan, dan interaksi dosen. Penjelasan adalah berikut:

a. Tipe interaksi pertama adalah dengan dosen yang menjadi fasilitasor active learning dan interaksi tatap muka yang terjadi pada suatu setting sosial. Akan tetapi dosenlah yang merancang dan mengelola urut-urutan pembelajaran dan menyeleksi media yang tepat sebelum berinteraksi dengan mahasiswa. Selanjutnya dosen menggunakan elearning www.unsil.ac.ad untuk meakukan pembelajaran jarak jauh dan pengumpulan 
tugas serta komunikasi secara online. Mahasiswa dapat berdiskusi dengan mahasiswa lain dan dengan mahasiswa dapat berdiskusi dengan mahasiswa lainnya dengan dosen pada waktu yang bersamaan sehingga akan terjadi komunikasi interpersonal dan feedback

b. Interaksi kedua adalah dengan muatan interaksi ini menjembatani interaksi kognitif dengan konsep konsep dan keterampilan yang termuat dalam modul pembelajaran. Modul tersebut disertai dengan petunjuk penggunaan dan mind mapping setap topik sehingga tujuan pembelajaran tergambara dengan jelas.

c. Terakhir, interaksi sosial dimaksudkan senbagai kemampuan pembelajar (siswa) untuk mempersepsikan diri mereka sebagai sebuah komunitas yang saling bergantung secara positif (positive interdependent, cooperation). Interaksi yang demikian itu dapat terjadi di keseluruhan proses pembelajaran karena mereka engerjakan tgas-tugasyang menuntut kerjasama. Sebagaimana diketahui dimensi interaksi (diskursus social). Makna ini kemudian dibagai diantara anggota-anggota kelompok yang ikut membangun pengetahuan bersama melalui tanggapan antar mereka sendiri. Ini sudah merupakan pencapaian level kognitif yang tinggi (Aviv, 2000).

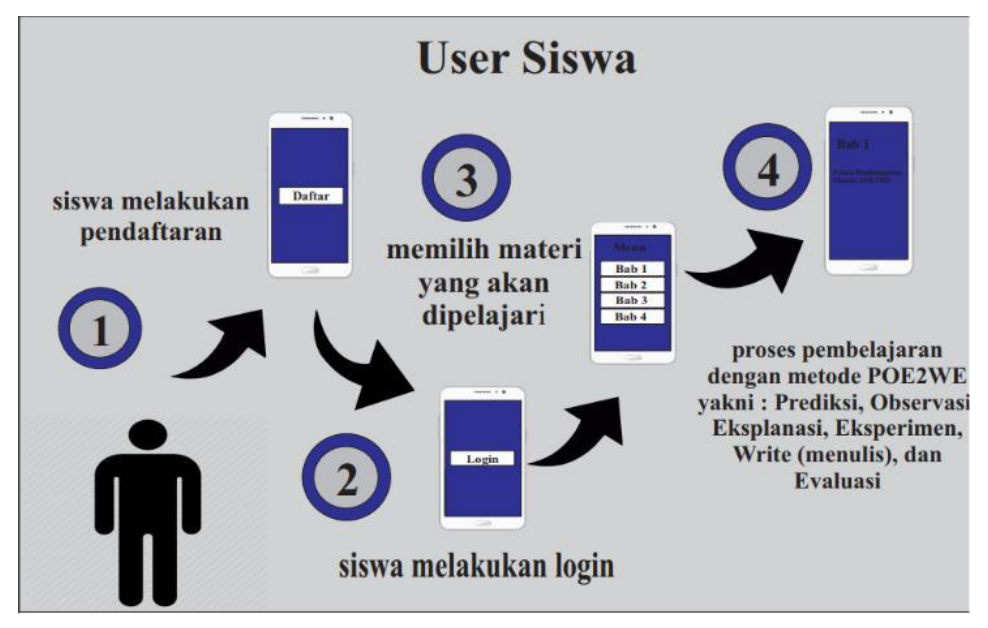

Penyajian E-learning berbasis web memungkinkan informasi perkuliahan menjadi real time dan bersifat interaktif.. Situs e-learning ini dapat diakses melalui alamat 'alearning.unsil.ac.id Melalui E-learning ini didapat:

Mata Kuliah Fisika Sekolah

\begin{tabular}{llll}
\hline No & Dosen & \multicolumn{2}{c}{ Mahasiswa } \\
\hline 1 & Menyusun Silabus & Mengakses informasi & dan materi \\
& & Perkuliahan
\end{tabular}


2 Meng-Upload Materi perkuliah

3 Memberikan Tugas kepad

Mahasiswa

4 Menerima pekerjaan Mahasiswa

5 Membuat tes/Quiz

Memberikan

6 nilai

7 Memonitor keaktifan mahasisw

8 Mengolah nilai mahasiswa

9 Berinteraksi dengan mahasiswa dan

Melal

sesaman dosen ui

diskusi dan chat
Meng- download materi perkuliahan

Melakukan transaksi tugas-tugas perkuliahan

Mengerjakan tugas

Mengerjakan tes/quiz

Melihat pencapaian hasil belajar

Melihat kehadiran

Melihat nilai

dengan

Berinteraksi

sesama

(Nana \& Surahman. 2019: 88-89)

\subsection{GOOGLE CLASSROOM}

Google Classroom merupakan ruang kelas google dimana media ini hanya sebagai alat bantu pembelajaran saja.Google Classroom dapat digunakan pada setiap ruang lingkup pendidikan yang bertujuan untuk menemukan solusi atas kesulitan yang dialami dalam membuat tugas tanpa menggunakan kertas (paperless). Perangkat lunak ini dikenal sebagai bagian dari Google Apps For Education (GAFE) sejak 12 Agustus 2014. Aplikasi ini dapat memudahkan pendidik dan peserta didik dalam melaksanakan proses pembelajaran yang lebih mendalam, hal ini disebabkan karena pendidik maupun peserta didik dapat mengumpulkan tugas, mendistribusi tugas dan menilai tugas tanpa terikat oleh batas waktu pelajaran. (Komariah.dkk,2019)

\subsection{Inovasi Pembelajaran}

Inovasi pembelajaran sebagai perubahan yang baru dalam meningkatkan kemampuan demi mencapai tujuan tertentu berupa praktik-praktik pendidikan. Tujuan tersebut berkaitan dengan usaha untuk memecahkan persoalan dalam pendidikan dan memperbaiki sistem pendidikan yang kurang sesuai dengan implementasinya (Shalikhah, 2017: 13). Selanjutnya inovasi pembelajaran sebagai suatu ide, gagasan, atau tindakan-tindakan di bidang kurikulum maupun 
pengajaran yang dianggap mengalami pembaharuan untuk memecahkan dan memberikan solusi terhadap permasalahan dalam pendidikan (Sanjaya, 2010: 317-318).

\subsection{Penerapan Model Blended POE2WE berbasis Google Classroom sebagai inovasi pembelajaran di Sekolah Menengah Atas di era Revolusi Industri 4.0}

Pada dasarnya, inovasi dalam pembelajaran yang menunjang kreativitas baik secara implisit dan eksplisit tetap menjelaskan pentingnya mengetahui berbagai informasi baik dari sumber media cetak maupun media elektronik yaitu internet (Ohman, 2011: 381). Salah satu masalah dalam proses pengajaran di sekolah yaitu bagaimana mengembangkan keterampilan siswa agar menjadi kreatif dan sesuai dengan bakatnya. Setiap siswa dilatih sesuai dengan keterampilan dan bakat yang dimiliki agar dapat meningkatkan motivasi. Keterampilan yang harus dimiliki oleh siswa berkaitan dengan penalaran verbal-numerik, pemikiran secara abstrak, mengingat informasi sesuai dengan keabsahan data (Cetinkaya, 2014: 3722-3723).

Penelitian yang dilakukan oleh Wicaksono \& Rachmadyanti (2017) menyatakan bahwa melalui penggunaan Google Classroom siswa menjadi lebih nyaman dan lebih aktif dalam mengkonstruksikan pengetahuannya. Penelitian yang dilakukan oleh Gunawan \& Sunarman (2018) secara umum tingkat keberhasilan dalam proses pembelajaran menggunakan Google Classroom sebesar $88 \%$ dari rancangan penelitian, pemecahan masalah yang dilakukan oleh peserta didik juga sesuai dengan ekspetasi yang diharapkan, kemampuan pemecahan masalah pada peserta didik semakin meningkat serta penggunaan Google Classroom mendapat respon yang baik dari peserta didik. Penggunaan Google Classroom efektif untuk dipergunakan dalam proses pembelajaran serta mampu mengembangkan pemecahan masalah pada peserta didik.

Penyajian E-learning berbasis Google Classroom memungkinkan informasi perkuliahan menjadi real time dan bersifat interaktif. Situs e-learning ini dapat diakses melalui aplikasi Google Classroom Melalui E-learning ini didapat:

\begin{tabular}{|c|c|c|}
\hline No & Guru & Peserta Didik \\
\hline \multirow[t]{2}{*}{1} & Menyusun Silabus & Mengakses informasi dan materi \\
\hline & & Pelajaran \\
\hline 2 & Meng-Upload Materi pelajaran & Meng- download materi pelajaran \\
\hline 3 & Memberikan & Melakukan transaksi tugas-tugas \\
\hline
\end{tabular}


Peserta Didik

4 Menerima pekerjaan Peserta Didik

5 Membuat tes/Quiz

Memberikan

6 nilai

7 Memonitor keaktifan Peserta Didik

8 Mengolah nilai mahasiswa

Berinteraksi dengan dan peserta

9 didik

sesama guru Melalui form

diskusi dan chat pelajaran

Mengerjakan tugas

Mengerjakan tes/quiz

Melihat pencapaian hasil belajar

Melihat kehadiran

Melihat nilai

dengan

Berinteraksi sesama

Peserta didik dan guru melalui forum

Diskusi

\section{KESIMPULAN}

Penerapan model Blended POE2WE berbasis Google Classroom sebagai inovasi pembelajaran Sekolah Menengah Atas di era Revolusi Industri 4.0 merupakan hal baru. Penerapan model ini mengarah ke e-learning sebagai jawaban atas tuntuutan di revolusi industry 4.0.

\section{UCAPAN TERIMA KASIH}

Terimaka kasih kepada Bapak Dr. Nana., S.Pd,.M,Pd selaku dosen mata kuliah yang telah memberikan bimbingan dan arahan untuk menyelesaikan jurnal ini, dan berterimakasih juga kepada rekan-rekan yang telah mebantu.

\section{DAFTAR PUSTAKA}

Aviv, R. (2000). Educational performance of ALN via content analysis. Journal of Asynchronous Learning Networks, 4(2), 53-72.

Cetinkaya, C. (2014). The effect of gifted students creative problem solving program on creative thinking. Social and Behavioral Sciences, 116, 3722-3723. Doi: 10.1016/j.sbspro.2014.01.830.

Gumay, O. P. U., \& Framanta, A. (2019). Penerapan Model Pembelajaran Talking Stick pada Mata Pelajaran Fisika Siswa Kelas X SMA Negeri Sukakarya. Jurnal Perspektif Pendidikan, 13(1), 65-72. 
Gunawan, F. I., \& Sunarman, S. G. (2018). Pengembangan Kelas Virtual Dengan Google Classroom Dalam Keterampilan Pemecahan Masalah (Problem Solving) Topik Vektor Pada Siswa Smk Untuk Mendukung Pembelajaran. In Prosiding Seminar Nasional Pendidikan Matematika Etnomatnesia.

Komariah.dkk. (2019). Pengaruh Penerapan Model PBL Berbantuan Media Google

Classroom Terhadap HOTS,Motivasi dan Minat Peserta Didik. Silampari Jurnal Pendidikan Ilmu Fisika.

Nana, N., \& Surahman, E. (2019). Pengembangan Inovasi Pembelajaran Digital Menggunakan Model Blended POE2WE di Era Revolusi Industri 4.0. In Prosding SNFA (Seminar Nasional Fisika dan Aplikasinya) (Vol. 4, pp. 82-90).

Permendikbud. (2013). Nomor 65 Tahun 2013 tentang Standar Proses.".

Rahmasari, G., \& Rismiati, R. (2013). E-learning pembelajaran jarak jauh di SMA.

Bandung: Yrama Widya.

Sanjaya, W. (2010). Kurikulum dan pembelajaran: Teori dan praktik Pengembangan Kurikulum Tingkat Satuan Pendidikakan (KTSP). Jakarta : Kencana.

Shalikhah, N. D., Primadewi, A., \& Iman, M. S. (2017). Media pembelajaran interaktif lectora inspire sebagai inovasi pembelajaran. WARTA LPM, 20 (1), 9-16.

Sukamto, B.C. (2012). "E-Learning Jaringan Komputer Berbasis Web dan Aplikasi Mobile." Jurnal Teknik Elektro 1(1): 75-78.

UUD RI. (2003). UUD RI No 20 Bab 1 Pasal 1 tentang Sistem Pendidikan Nasional.

Wicaksono, V. D., \& Rachmadyanti, P. (2017). Pembelajaran Blended Learning Melalui Google Classroom Di Sekolah Dasar. Seminar Nasional Pendidikan PGSD UMS \& HDPGSDI Wilayah Jawa (2017). 